\title{
COPPER OXIDE OF PLASMA-CHEMICAL SYNTHESIS FOR DOPING SUPERCONDUCTING MATERIALS
}

\author{
A.V. USHAKOV \\ Department of UNESCO, Siberian Federal University, Krasnoyarsk,660041, Russian Federation \\ Reshetnev Siberian State Aerospace University, Krasnoyarsk, 660037 Russia \\ ushackov@mail.ru \\ I.V. KARPOV \\ Department of UNESCO, Siberian Federal University, Krasnoyarsk,660041, Russian Federation \\ Reshetnev Siberian State Aerospace University, Krasnoyarsk, 660037 Russia \\ karpovsfu@mail.ru \\ A.A. LEPESHEV \\ Department of UNESCO, Siberian Federal University, Krasnoyarsk,660041, Russian Federation \\ sfu-unesco@mail.ru \\ L.Yu. FEDOROV \\ Department of UNESCO, Siberian Federal University, Krasnoyarsk,660041, Russian Federation \\ 1401-87@mail.ru
}

\begin{abstract}
Properties of nanodispersed powder copper oxide, synthesized during arc sputtering of copper in a gas mixture of low pressure oxygen, were studied. It was shown that the particles possess nanometer size and narrow size distribution. The issue of reduction, recrystallization and sintering of nanodispersed powder were discussed.
\end{abstract}

Keywords: nanoparticles, vacuum arc, high-temperature superconductor, copper oxide, low pressure arc discharge.

\section{Introduction.}

All techniques, based on a melting process and used for producing coarse-grained YBCO ceramics, are characterized by a peritectic reaction at $T_{\mathrm{p}}=1015^{\circ} \mathrm{C}$, which resulted in formation of phase 123 from phase 211 and a liquid component. The main problems of this technology are: (a) very low rate of crystallization; $(b)$ necessity to control temperature gradients in the high-temperature process, and (c) limited size of the produced single domains, followed by microcracks, disorientation and heterogeneous composition. Improvements can be achieved by varying the process parameters and using a dopant $[1$, 2]. Applying high-temperature superconductors requires high grain ordering or developing a perfect texture of the sample, that is easily achieved in smaller samples, due to the presence of temperature gradients. High gradients, providing better ordering, lead to inevitable microcracking, in particular, because of differences in the coefficients of thermal expansion (CTE) between phase 123 and the secondary phases $\left(\mathrm{BaCuO}_{2}, \mathrm{CuO}\right)$, deposited on intercrystallite borders. Microcracks, perpendicular to plane $a b$ could be developed during cooling or calcination of the sample, significantly reducing its superconducting properties. Further, chemical heterogeneity in the long samples is formed by intersection of the corresponding hot zones and appears as a sharp decrease of $\mathrm{Ba}$ and $\mathrm{C}$, which 
correlates with an increase of phase 211. Addition of nanosized materials such as $\mathrm{CuO}$, increasing the melting viscosity, could significantly restrict this phenomenon. Copper oxide nanoparticles are commonly synthesized by wet chemical processes [35]. However, it is not easy to ensure the homogeneity and crystallinity of the nanoparticles being fabricated by using such methods. This is because wet chemical processes involve low temperatures. In contrast to wet chemical processes, thermal plasma-based ones involve evaporation of the constituent metals at temperatures higher than $10,000 \mathrm{~K}$, followed by rapid condensation of the gas phases [6-10]. Thermal plasma-based processes have other advantages over wet chemical processes. One is that, using these processes, it is possible to prevent adding impurities to the end products; this is different from the case with wet chemical processes [11]. So far, a number of thermal plasma based processes have been developed. Among them, the vacuum arc plasma evaporation (VAPE) method is commonly used for deposition of thin films [12] and nanoparticles fabrication [13-16].

The aim of this work is to study the thermalphysical properties of nanosized powder (NP) of copper oxide synthesized in the plasma of low pressure arc discharge in order to improve the properties of coarse-grained YBCO ceramics.

\section{Experimental technique}

Experimental equipment and the dependence of the powder properties on the spraying conditions are discussed in detail in [17-19]. The arc evaporator has the following characteristics: discharge current of 500 A, intensity of the longitudinal magnetic field on the surface of the cathode, produced by the focusing coil, of $6663.2 \mathrm{~A} / \mathrm{m}$. Electrorefining copper M0 was used as a sputtering cathode. Gaseous $\mathrm{O}_{2}$ was put in the chamber after preliminary evacuation to the residual pressure of $1 \mathrm{MPa}$ for providing the plasma chemical reactions. Evaporation was carried out at oxygen pressure of $10 \mathrm{~Pa}$. The cathode was heated up to $500 \mathrm{~K}$ before the evaporation. The copper oxide powders, at the indicated pressure, were gradually developed for $10 \mathrm{~min}$. Morphological composition of the samples was studied by JEOL JEM-2100 transmission electron microscope. Samples for electron microscopy studies were prepared as follows: the powder was placed in isopropyl alcohol, and then it was dispersed in an ultrasonic bath for $2 \mathrm{~min}$. Then a drop of the solution was dripped on a carbon film substrate, located on the electron-microscopic supporting grid. The thickness of the carbon film substrate was $10-15 \mathrm{~nm}$.

The phase composition of the obtained samples was studied using Advance D8 X-ray diffractometer in $\mathrm{CuK} \alpha$ monochromatic radiation. Scanning was performed at room temperature in the range of angles $30-120^{\circ}$ by $2 \theta$ with a step of 0.04 . Microstructural characteristics and parameters of the elementary cell were determined using X-ray full-profile analysis by the Rietveld method [20]. A software complex, based on a modified and corrected version of software developed for studying structures by the Rietveld method - DBWS-9006PC, was used [21]. The TCHpseudo-Voigt function [22], which takes into account the influence of the instrument application factor, micro-stress and crystallite size on the peak shape, was used for simulating the profile of X-ray images.

The specific surface area was measured by the BET method. The thermal properties of the NP were investigated using a Q-1500D derivatograph. The sample weight was $100 \mathrm{mg}$. The sample was heated at $10{ }^{\circ} \mathrm{C} / \mathrm{min}$ in the temperature range from 291 to 1273 $\mathrm{K}$.

The study of the initial stage of the NP sintering in terms of their chaotic distribution was performed by the BET method. Chaotically distributed powder was heated on the substrate by means of oxygen plasma arc on the copper cathode. The substrate temperature was measured by using a thermocouple. The dependence of the specific surface area of the powder $(S)$ on the temperature after 15 minutes of isothermal holding when the shrinkage of the samples at this temperature is practically over, was used to identify the beginning of the particles sintering.

\section{Results and discussion}

Fig. 1 shows a typical view on the sample. The powder is an ensemble of strongly agglomerated particles of irregular shape with a size of 4 to $9 \mathrm{~nm}$. Formations of up to $15 \mathrm{~nm}$ are also met, but it seems that they are agglomerated from smaller particles. Such agglomerates cannot be disaggregated. The particle shape is usually close to the spherical one. Studying the size distribution has shown that the NP 
has a log-normal distribution and an average particle size is of $6 \mathrm{~nm}$. The deviation from the average size is not more than $40 \%$.

Fig. 2 (1) shows an X-ray image of the synthesized copper oxide NP. The sample is $\mathrm{CuO}$ monoclinic phase with lattice parameters of $a=0.4632 \mathrm{~nm}, b=$ $0.3401 \mathrm{~nm}, c=0.5045 \mathrm{~nm}$, which are significantly less than the standard parameters of $\mathrm{CuO}$. The form of peaks in the X-ray image indicated the presence of two fractions, that differ in size of the crystallites, in the sample. This conclusion was based on the fact, that the diffraction maxima have anomalously sharp peaks under a large integral width. Such a complex shape can be explained by a superposition of two peaks that greatly differ in width. Therefore, at a full-profile precision, two fractions with different crystallite sizes and their different percentages were introduced into the model. A full-profile precision of microstructural parameters revealed that the basic mass of the sample $(\sim 98 \%)$ represents a fraction with an average crystallite size of $4 \mathrm{~nm}$. The remaining $2 \%$ of the material is a coarse-grained fraction with crystallite size of more than $150 \mathrm{~nm}$.

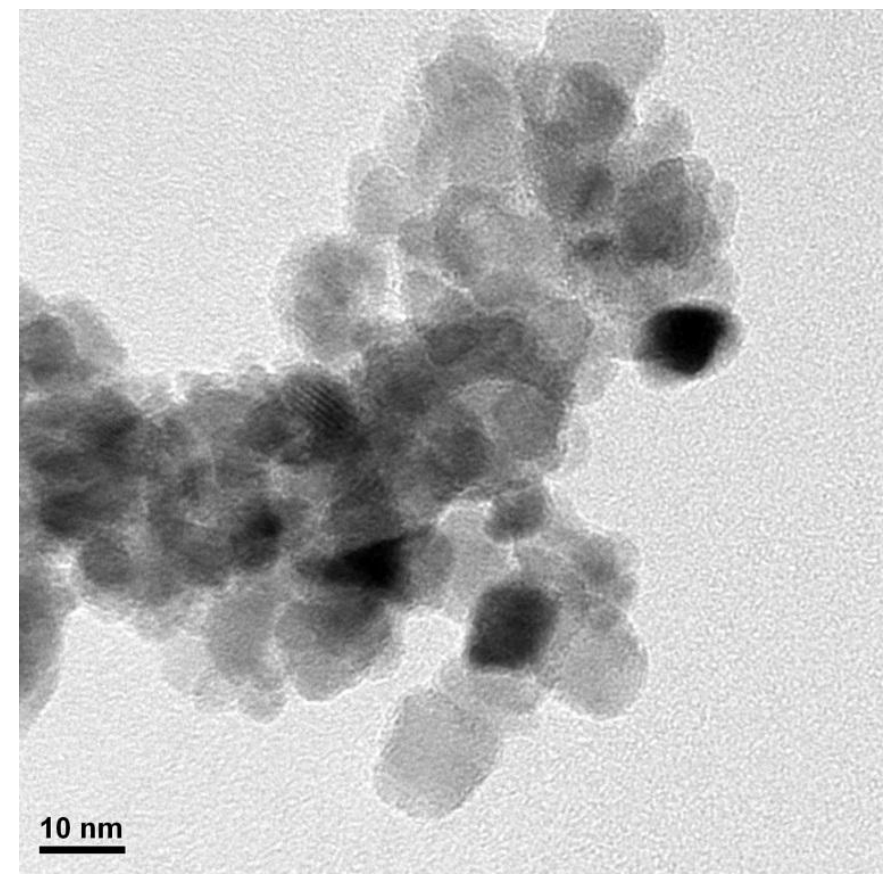

Fig. 1. NP sample of copper oxide produced in an arc discharge of low pressure

The specific surface area, calculated based on the low-temperature adsorption isotherm of argon, was $446 \mathrm{~m}^{2} / \mathrm{g}$. Using the well-known relationship between the surface area $S$, where pycnometric density $\gamma=6.51$ $\mathrm{g} / \mathrm{cm}^{3}$ and an average particle size $d=6 / \gamma S$, the result will be obtained as equal to $3 \mathrm{~nm}$.

The powder weight is increased for 2-3 minutes in contact with the atmosphere. The maximum change of the powder weight was $16 \mathrm{wt} . \%$.

The results of the derivatographic analysis are shown in Fig. 3. Intensive evaporation of water occurs in the temperature range from 333 to $443 \mathrm{~K}$, it is evidenced by the reduction in weight of the sample to 9 wt. \% (see the thermogravimetric curve), although the DTA curve has no explicit minimum. Under the temperature of $536 \mathrm{~K}$, a small exothermic effect occurs, which is not accompanied by a change in the weight of the sample. Under the temperature range from 630 to $763 \mathrm{~K}$, a slight reduction in weight (not more than $2 \mathrm{wt} . \%$ ) occurs, which is accompanied by a strong exothermic effect with a maximum at the temperature of $713 \mathrm{~K}$. Further increase in temperature does not lead to significant thermal effects. Fig. 2 (curve 2) shows an X-ray image of the sample heated to $543 \mathrm{~K}$. In addition to $\mathrm{CuO}$, reflections corresponding to the cubic phase, $\mathrm{Cu}_{2} \mathrm{O}$ appear in the sample as well.

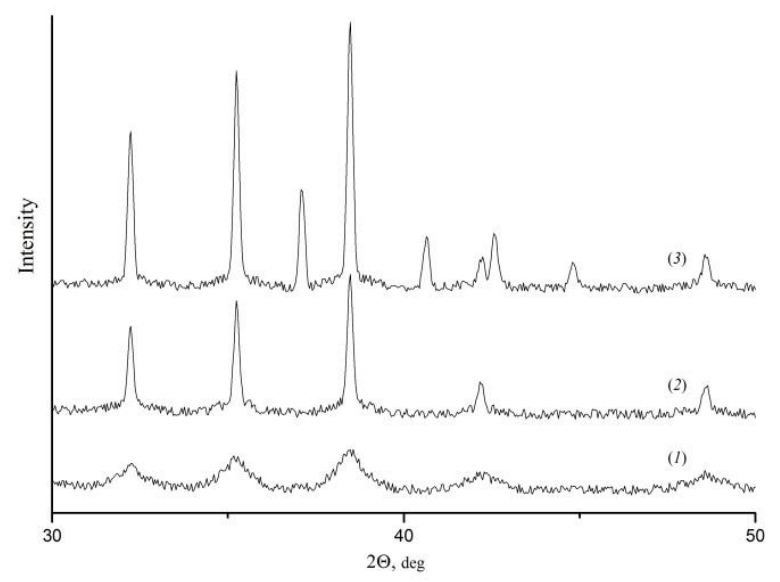

Fig. 2. XRD of the sample: 1 - experimental X-ray of source sample; 2 - X-ray of a sample heated to $543 \mathrm{~K} ; 3$ - X-ray of the sample heated to $800 \mathrm{~K}$

In addition, the narrow peaks corresponding to crystallites larger than $60 \mathrm{~nm}$ appear on the background of blurred lines referred to $\mathrm{CuO}$ compounds. When the sample is heated to the temperature of $800 \mathrm{~K}, \mathrm{CuO}$ continues to lose oxygen, turning into $\mathrm{Cu}_{2} \mathrm{O}$. The corresponding $\mathrm{X}$-ray image is shown in Fig. 2 (3). 
Fig. 3 shows the dependence of the specific surface of copper oxide HM under the heat treatment. As the figure shows, the characteristic curve of both correlations corresponds to one value of the temperature $(470 \mathrm{~K})$. The error in determining the initial temperature of sintering $\left(T_{\text {sint }}\right)$ oxides using the proposed method, at high values of $S\left(100 \mathrm{~m}^{2} / \mathrm{g}\right.$ and more) when a bending curve fragment in the temperature dependence is exhibited more sharply, does not exceed $3 \%$. The measurement results for the copper oxide approximated by a linear correlation, corresponds to the following analytical equation [23]:

$$
T_{\text {sint }}=T_{0} \cdot e^{-c\left(d_{0}-d_{g}\right) / d_{g}},
$$

where $T_{0}$ is the temperature at the initial stage of the massive particles sintering;

$c$ is a constant which is probably a characteristic of the nature of the substance and the surface layer energy state;

$d_{o}$ is a conditional resolution of massive particles.

The numerical values of these quantities for $\mathrm{CuO}$ are: $T_{0}=1030 \mathrm{~K}, d_{0}=1 \mathrm{~mm}, c=6,2 \cdot 10^{-6}$.

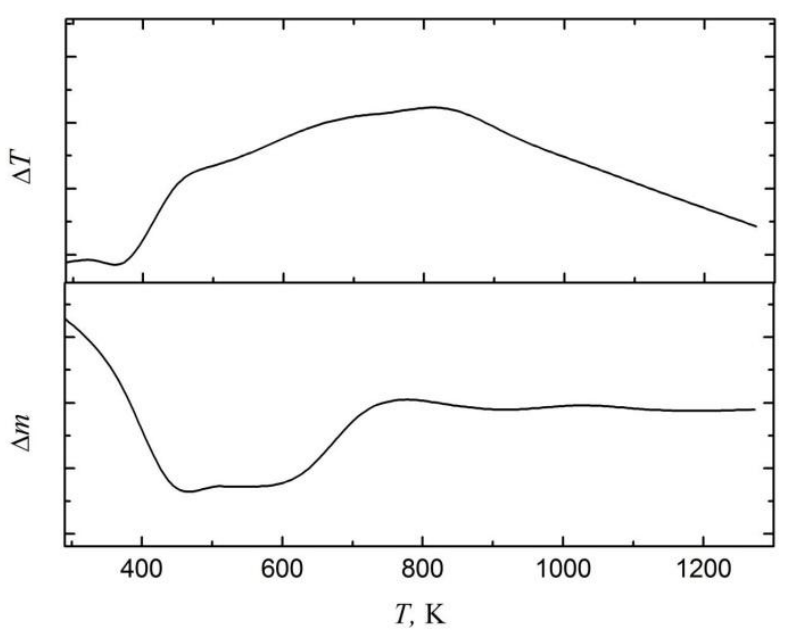

Fig. 3. Derivatograph of copper oxide NP

The temperature of sintering at the initial stage, calculated by the formula, differs from the formula, obtained experimentally, by 50 degrees. This is probably due to the fact, that a significant contribution to the process of sintering the corresponding copper oxide NP, synthesized in the low-pressure arc discharge, provides the surface effects that are considered in the formula as constant $c$.
Based on the results of the NP copper oxide behavior in the temperature range from 443 to $713 \mathrm{~K}$, it can be concluded, that two exothermic and one endothermic processes occur: recrystallization, recovery, and sintering. The recrystallization has a particularity such as the property to maintain a significant deviation of the lattice parameter from the standard value. The work [24] shows that nonequilibrium conditions for nanopowder production and their small size determine particularities in the crystalline structure and defects in definite powder objects.

Deformation of the particles can be caused by the influence of the capillary forces, where the static displacements (due to their inhomogeneous deformation behavior in small particles) makes the greatest contribution to the mean square deviation. Unfortunately, there is no data found in the literature about lattice spacing for copper oxide with a specific surface area of more than $95.4 \mathrm{~m}^{2} / \mathrm{g}$. However, the correlation of the lattice parameter on the specific surface area is in satisfactory agreement with the data obtained for the synthesized NP.

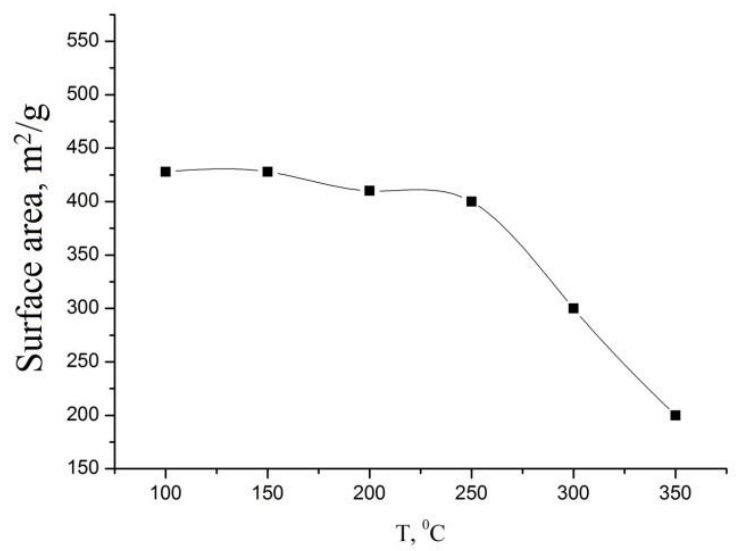

Fig. 4. Influence of heat treatment of copper oxide HM on its surface area

The work [25] reported a substantial anisotropic deformation of the crystal lattice during the annealing of boron nitride powder with an average particle size of $5.3 \mathrm{~nm}$. It is shown that a significant decrease in the lattice parameter is caused by structural stress heterogenious by volume due to the size factor. Thus, it can be assumed that the most probable causes of the lattice deformation in the annealed copper oxide are: the lack of completeness of the crystal lattice formation process and, consequently, increasing the 
concentration of nonequilibrium atom vacancies due to the abrupt nature of crystallization; the additional impact of surface pressure due to significant surface energy contribution to the total free energy of the small particles, where the structural deformation can be uniform according to the size of the particles.

\section{Conclusion.}

1. The copper oxide NP has an average particle size of $6 \mathrm{~nm}$, a deviation from the average does not exceed $40 \%$.

2. The NP is a $\mathrm{CuO}$ monoclinic phase with lattice parameters as follows: $a=0.4632 \mathrm{~nm}, b=0.3401 \mathrm{~nm}$, $c=0.5045 \mathrm{~nm}$, which are significantly less than the parameter of the standard $\mathrm{CuO}$.

3. The specific surface of NP was $446 \mathrm{~m}^{2} / \mathrm{g}$.

4. The temperature range was from 443 to $713 \mathrm{~K}$, two exothermic and one endothermic processes occur, they are: recrystallization, recovery and sintering.

5. The quantitative dependence has been found for the temperature limits for the heat treatment of chaotically distributed $\mathrm{CuO}$ powders on the average particle size, for which particles coarsening begins due to the process of sintering, for the periods typical of traditional technological processes (1-10 hours).

\section{Acknowledgments}

This work was supported by the Russian Foundation for Basic Research (projects no. 15-08-02132).

\section{References.}

1. A.V. Ushakov, I.V. Karpov, A.A. Lepeshev, M.I. Petrov, L.Yu. Fedorov, Study of Magnetic Flux Pinning in Granular $\mathrm{YBa}_{2} \mathrm{Cu}_{3} \mathrm{O}_{7-\mathrm{y}} / \mathrm{nanoZrO}_{2}$ Composites. JETP Letters. 99 (2014), pp. 99-103.

2. A.V. Ushakov, I.V. Karpov, A.A. Lepeshev, M.I. Petrov, Enhancing of magnetic flux pinning in $\mathrm{YBa}_{2} \mathrm{Cu}_{3} \mathrm{O}_{7-\mathrm{x}} / \mathrm{CuO}$ granular composites. J. Appl. Phys. 118 (2015). p.023907.

3. L. Liu, K. Hong, T. Hu, M. Xu, Synthesis of Aligned Copper Oxide Nanorod Arrays by a Seed Mediated Hydrothermal Method. J of Alloys and Compounds 511 (2012), pp. 195-197.

4. S. Srivastava, M. Kumar, A. Agrawal, S.K. Dwivedi, Synthesis and Characterisation of Copper Oxide nanoparticles. IOSR Journal of Applied Physics (IOSR-JAP) 5 (2013), pp. 61-65.

5. Shah M. Asharf, M.S. Al-Ghamdi, Preparation of Copper $(\mathrm{Cu})$ and Copper Oxide $\left(\mathrm{Cu}_{2} \mathrm{O}\right)$ Nanoparticles under Supercritical Conditions. Materials Sciences and Application 2 (2011), pp. 977-980.
6. R.K. Swarnkar, S.C. Singh, R. Gopal, Effect of aging on copper nanoparticles synthesized by pulsed laser ablation in water: structural and optical characterizations. Bull. Mater. Sci. 34 (2011), pp. 1363-1369.

7. J. Musil, P. Baroch, High-rate pulsed reactive magnetron sputtering of oxide nanocomposite coatings. Vacuиm 87 (2013), pp. 96-102.

8. K. Nadeem, H. Krenn, T. Traußnig, R. Würschum, D.V. Szabó, I. Letofsky-Papst, Spin-glass freezing of maghemite nanoparticles prepared by microwave plasma synthesis. $J$. Appl. Phys. 111 (2012), p. 113911.

9. P. Synek, O. Jašek, L. Zajíčková, Study of Microwave Torch Plasmachemical Synthesis of Iron Oxide Nanoparticles Focused on the Analysis of Phase Composition. Plasma Chem. Plasma Process. 34 (2014), p. 327.

10. P. Lei, A. Boies, S. Calder, S. Girshick, Thermal Plasma Synthesis of Superparamagnetic Iron Oxide Nanoparticles. Plasma Chem. Plasma Process. 32 (2012), p. 519.

11. Y. Xua, J. Yang, M. Demura, T. Hara, T. Hirano, Y. Matsushita, Tanaka, Y. Katsuya, Fabrication of $\mathrm{Ni}-\mathrm{Al}$ nanoparticles via vacuum arc plasma evaporation and their catalytic properties for $\mathrm{CO}$ oxidation. Applied Catalysis A: General 478 (2014), pp. 165-174.

12. M. Zhang, X. Tu, J. Wang, T. Fang, Y. Wang, X. Xu, M. Zhang, Y. Chen, Hydrothermal syntheses of $\mathrm{CuO}$, $\mathrm{CuO} / \mathrm{Cu}_{2} \mathrm{O}, \mathrm{Cu}_{2} \mathrm{O}, \mathrm{Cu}_{2} \mathrm{O} / \mathrm{Cu}$ and $\mathrm{Cu}$ microcrystals using ionic liquids. Chemical Research in Chinese Universities 32 (2016), pp. 530-533.

13. V.Yu. Novikov, I.Yu. Goncharov, V.S. Zakhvalinskii, A.Y. Kolpakov, M.B. Ivanov, D.A. Kolesnikov, The electrical properties of coating obtained by vacuum arc deposition. Results in Physics 5 (2015), pp. 72-73.

14. A.A. Ashkarran, M. Kavianipour, S.M. Aghigh, S.A. Ahmadi Afshar, S. Saviz, A. Iraji Zad, On the Formation of $\mathrm{TiO}_{2}$ Nanoparticles Via Submerged Arc Discharge Technique: Synthesis. Characterization and Photocatalytic Properties. J Clust Sci. 21 (2010), p. 753.

15. A.V. Ushakov, I.V. Karpov, A.A. Lepeshev, L.Yu. Fedorov, A.A. Shaikhadinov, Plasmachemical Synthesis and Basic Properties of $\mathrm{CoFe}_{2} \mathrm{O}_{4}$ Magnetic Nanoparticles. Technical Physics 61 (2016), p. 103.

16. A.V. Ushakov, I.V. Karpov, A.A. Lepeshev, M.I. Petrov, L.Yu. Fedorov, Specific Features of the Behavior of Electroarc $\mathrm{CuO}$ Nanoparticles in a Magnetic Field. Physics of the Solid State 57 (2015), pp. 919-923.

17. I.V. Karpov, A.V. Ushakov, L.Yu. Fedorov, A.A.Lepeshev, Method for Producing Nanomaterials in the Plasma of a Low Pressure Pulsed Arc Discharge. Tech. Phys., 84 (2014), pp. 559-563.

18. L.Yu. Fedorov, I.V. Karpov, A.V. Ushakov, A.A. Lepeshev, Influence of Pressure and Hydrocarbons on Carbide Formation in the Plasma Synthesis of TiC Nanoparticles. Inorganic Materials, 51 (2015), pp. 25-28. 19. A.A. Lepeshev, I.V. Karpov, A.V. Ushakov, L.Yu. Fedorov, A.A. Shaikhadinov, Synthesis of Nanosized Titanium Oxide and Nitride Through Vacuum Arc Plasma Expansion Technique. International Journal of Nanoscience. 14 (2015). p. 1550027.

20. H.M. Rietveld, Profile Refinement Method for Nuclear and Magnetic Structures. J. Appl. Cryst. 2 (1969), pp. 65-71. 
21. D.B. Wiles, R.A. Young, New Computer Program for Rietveld Analysis of X-ray Powder Diffraction Patterns. $J$. Appl. Cryst. 14 (1981). pp. 149-151.

22. P. Thompson, D.E. Cox, J.B. Hastings, Rietveld refinement of Debye-Scherrer synchrotron X-ray data from $\mathrm{Al}_{2} \mathrm{O}_{3}$. J. Appl. Cryst. 20 (1987), pp. 79-83.

23. V.M. Batenin, I.I. Klimovskiy, G.V. Lisov, V.N. Troitsky, Microwave plasma generators. Moscow: Energoatomizdat, 1988. 224 p. [In Russ]

24. V.N. Troitsky, O.M. Grebtsova, V.M. Berestenko, Hightemperature synthesis and properties of refractory compounds. Physics and Chemistry of Materials Processing. 6 (1980), pp. 13-15.

25. R.A. Andrievsky, Powder Materials. Moscow: Metallurgy, 1991. 207 p. [In Russ] 